\begin{tabular}{|c|c|c|}
\hline & Int.J.Curr.Microbiol.App.Sci (2016) 5(12): 660-671 & \\
\hline & International Journal of Current Microbiology and Applied Sciences & \\
\hline & ISSN: 2319-7706 Volume 5 Number 12 (2016) pp. 660-671 & \\
\hline $\begin{array}{l}\text { EXCELLENT } \\
\text { PUBLISHERS }\end{array}$ & & 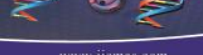 \\
\hline
\end{tabular}

Original Research Article

http://dx.doi.org/10.20546/ijcmas.2016.512.074

\title{
Characterization of Carbapenem Resistant Acinetobacter baumannii causing Ventilator associated Pneumonia in ICUs of Zagazig University Hospitals, Egypt
}

\author{
Ghada E. Amr ${ }^{1 *}$ and Ghada M. Abdel Razek ${ }^{2}$ \\ ${ }^{1}$ Departments of Clinical Pathology, Faculty of Medicine, Zagazig University, Egypt \\ ${ }^{2}$ Anaesthesia and Intensive Care, Faculty of Medicine, Zagazig University, Egypt \\ *Corresponding author
}

Keywords

Acinetobacter baumannii, blaOXA-23, VAP.

Article Info

Accepted:

26 November 2016

Available Online:

10 December 2016

\section{A B S T R A C T}

Ventilator associated pneumonia (VAP) affects approximately $30 \%$ of intubated mechanically ventilated patients in intensive care units (ICUs) worldwide. Acinetobacter baumannii causing VAP is often resistant to a wide variety of antibiotics including carbapenems that have been considered the drug of choice for the treatment for this infection. To characterize A. baumannii as a cause of VAP in our ICUs and to study its incidence, antimicrobial resistant profile and to investigate the presence of carbapenem hydrolyzing class $D \beta$-lactamase genes as a cause of carbapenem resistance among the studied isolates. A total of $44 \mathrm{~A}$. baumannii isolates were recovered from 135 endotracheal aspirate samples of VAP patients. A. baumannii were identified by Matrix-assisted laser desorption ionization-time of flight mass spectrometry and its antimicrobial susceptibility was investigated by VITEK 2 instrument and E test, class D $\beta$ - lactamase genes were investigated by multiplex PCR technique. All A. baumannii isolates were multidrug resistant;75\% were resistant to carbapenems while colistin remains the most active compound among the studied isolates with sensitivity rate of $93.2 \%$. Multiplex PCR results showed that all A. baumannii isolates were positive for $b l a_{\text {OXA-51- }}$ like gene while $69.7 \%$ of carbapenems resistant isolates were positive for $b l a_{\text {OXA-23 }}$ like gene, $b l a_{\text {OXA-58 }}$ and $b l a_{\text {OXA-24 }}$ like genes were not detected in any of the studied isolates. This study highlights the emergence of carbapenem resistant $A$. baumannii as a cause of VAP in our ICUs that was mostly due the presence of $b l a_{\text {OXA-23 like gene. }}$

\section{Introduction}

Ventilator-associated pneumonia (VAP) is a common serious healthcare-associated infection among patients in intensive care units (ICUs) who have endotracheal intubation or a tracheostomy for mechanical ventilation, affecting an estimated 10-30\% of ventilated patients worldwide (Bantar et al., 2008). Acinetobacter baumannii (A. baumannii)is an important opportunistic pathogen associated with ventilatorassociated pneumonia and other variety of nosocomial infections in ICUs as central 
line-associated bloodstream infections, urinary tract infections and wound infections(Peleg et al., 2008). Multidrugresistant (MDR) A. baumannii isolates have been increasingly reported worldwide that are associated with an enhanced risk of mortality and prolonged durations of hospitalization (Antunes et al., 2014, Lemos et al., 2014).

Carbapenems (e.g., imipenem, meropenem) have historically retained the best antibacterial activity and are considered as the treatment of choice for this pathogen however nowadays clinicians are very concerned for the carbapenemase producer A. baumannii, the increasing rates of this resistance worldwide limit the range of therapeutic alternatives (Dai et al., 2013).

Carbapenem resistance in A. baumanniiis most commonly caused by the production of carbapenemases; enzymes belonging to Ambler classes B, A and D (Bush and Jacoby, 2010). The most prevalent mechanism is carbapenem hydrolyzing class D $\beta$-lactamases (CHDLs) that can be divided into four main subgroups including OXA51, OXA 23, OXA24 and OXA 58, which are encoded by the intrinsic bla $a_{\text {OXA-51- }}$ like and the acquired carbapenemase genes including $b l a_{\text {OXA-23-like, }}$ bla $a_{\text {OXA-24-like and }}$ $b l a_{\text {OXA-58- }}$ like genes respectively (Poirel and Nordmann, 2006, Merkier and Centron, 2006).

The aim of this study was to characterize $A$. baumannii as a major cause of VAP in patients admitted to the ICUs of Zagazig University hospitals and to investigate its incidence, illustrate its antimicrobial resistance pattern and the genetic mechanisms of resistance involved in carbepenam resistant isolates by investigating the presence of $b l a_{\text {OXA-51 }}$, $b a_{\text {OXA- } 23}, b_{\text {OXA-24 }}$, bla $_{\text {OXA-58 }}$ like gens.

\section{Materials and Methods}

A total of 44 A. baumannii isolates were recovered from 135 endotracheal aspirate samples of patients with VAP admitted to the ICUs of Zagazig University Hospitals over 18months period (September 2014 to February2016). Approval for this study was obtained from Research Administration and Research Ethics Committee of Faculty of Medicine, Zagazig University. The collected samples were transported to the microbiology laboratory and inoculated on Mac Conkey agar, blood agar and chocolate agar plates that incubated in aerobic, $\mathrm{CO}_{2}$ condition at $37^{\circ} \mathrm{C}$ for $24-48$ hours.

\section{Identification}

All the organisms were identified by Matrixassisted laser desorption ionization-time of flight mass spectrometry (MALDI-TOF MS) using the VITEK MS system (Biomerieux. Inc, Durham, USA).A. baumannii isolates were further investigated by:

\section{Antibiotic susceptibility testing}

Antibiotic susceptibility testing was carried out using Vitek 2 System (card no 222) for Gram negative bacilli (Biomerieux. Inc, Durham, USA) in accordance with the guidelines of the Clinical and Laboratory Standards Institute (CLSI, 2012), the following antibiotics were included: amikacin, aztreonam, cefepime, ceftazidime, ciprofloxacin, colistin, gentamicin, imipenem, meropenem, minocyclin, pefloxacin, piperacillin, piperacillin/ tazobactam, rifampicin, ticarcillin, ticarcillin/clavulanic acid, tobramycin, and sulfamethoxazole. Susceptibility of $A$. baumannii isolates to imipenem and meropenem was confirmed Etest strips (Biomerieux, France) that were performed according to the manufacturer's instructions. 


\section{PCR}

All A. baumannii isolates were analyzed by multiplex PCR to detect bla $a_{\mathrm{OXA}-51-\text { like, }}$ bla $a_{\text {OXA-23-like, }}$ bla $a_{\text {OXA-24-like }}$ and bla OXA-58- $^{-}$ like genes as follow:

DNA was extracted from isolated $A$. baumannii colonies by using QIAamp ${ }^{\circledR}$ DNA Mini kit (Qiagen GmbH, Germany), for DNA amplification Qiagen multiplex plus kit (Qiagen, Hilden, Germany) were used as described by the manufacture. PCR amplification conditions were as follows: initial denaturation at $94^{\circ} \mathrm{C}$ for 3 mins followed by 30 cycles of amplification. Each cycle consists of $25 \mathrm{~s}$ at $94^{\circ} \mathrm{C}, 40 \mathrm{~s}$ at $52^{\circ} \mathrm{C}$ and $50 \mathrm{~s}$ at $72^{\circ} \mathrm{C}$ with a final extension of 5 min at $72^{\circ} \mathrm{C}$. The amplified PCR products were visualized on $2 \%$ agarose gel stained with ethidium bromide and examined under ultraviolet light; the molecular size marker is a 100-bp ladder (NEB, Frankfurt am Main, Germany). A single DNA band at $353 \mathrm{bp}$ was recorded as positive for the bla $a_{\mathrm{OXA}-51^{-}}$ like gene and at $501 \mathrm{bp}$ was recorded as positive for the bla $a_{\text {OXA-23-like gene, for }}$ bla $a_{\text {OXA-58 }}$ like and $b l a_{\text {OXA-24 }}$ like genes bands were expected to be at599 bp and $246 \mathrm{bp}$ respectively. Primers used in this study are shown on table 1 .

\section{Statistical analysis}

Data were analyzed using SPSS 20. Chi Square was used to compare categorical variables. $\mathrm{P}$ value of 0.05 was considered statistically significant

\section{Results and Discussion}

A. baumannii was the most common isolated organism from endotracheal aspirate samples of all VAP patients (44/135) 32.6\%, followed by Klebsiella 23.7\% (32/135), Staphylococci $\quad 22.2 \% \quad$ (30/135),
Pseudomonas $14.8 \%$ (20/135), E. coli which represent $6.7 \%(9 / 135)$.

Hospitalization for more than 14 days, prior use of antibiotics were identified as significant risk factors for $A$. baumannii resistant to carbapenems (P0.016, P0.012 respectively), while age and sex were not significant risk factors (table 2)

\section{Antimicrobial susceptibility}

The resistant rate of carbapenem resistant $A$. baumannii (CRAB) to impenim was $75 \%$ (33) and to meropenim was $72.7 \%$. All $A$. baumannii showed $100 \%$ resistant to cefepime, ceftazidime, aztreonam, pipracillin and trimethoprim/ sulfemethoxazole. The resistance to antibiotics were as follow in a descending order: pipracillin/ tazobactam95.5\% (42), ticarcillin $93.2 \%$ (41), ticarcillin/clavulanic acid $88.6 \%,(39)$, ciprofloxacin88\%(39), pefloxacin $84.1 \%$ (37), gentamycin $75 \%$ (33), tobramycin $72.7 \%(42)$, minocycline $70 \%$ (31), amikacin 57\%(25), rifampicin $34.1 \%$ (15),colistin $6.8 \%$ (3). Percentages of antimicrobial resistance among the studied A. baumanni isolates are illustrated in (figure 1).

Colistin was the most active antibiotic against isolated $A$. baumanni (sensitivity was 93.2\%). All A. baumannii isolates (100\%) were multidrug resistant (MDR). These isolates sensitivity results to imipenem and meropemem were confirmed by $\mathrm{E}$ test and reported as resistant when MIC> $16 \mathrm{~g} / \mathrm{ml}$.

Molecular analysis of carbapenem
resistance genes by PCR All the 44 A. baumannii isolates were positive for the bla $a_{\mathrm{OXA}-51}-$ like gene $(100 \%)$, among 33 impenim resistant isolates there 
were $23(69.7 \%)$ positive isolates for $b l a_{\text {OXA- }}$ 23-like gene, while $10(30.3 \%)$ were not carrying this gene. On the other hand 11 $(25 \%)$ sensitive isolates to imipenem were also negative to bla $a_{\text {OXA-23 }}$ gene. None of $A$. baumannii isolates were positive for $b l a_{\text {OXA- }}$ 24 or bla $a_{\text {OXA-58 }}$ like genes.

Nowadays VAP is one of the most common infections in the intensive care units (ICUs), increasing the length of stay of patients in these units, the cost of the treatment, and the risk of death.(Baxter, 2005).

A. baumannii has probably been the most frequently isolated bacterium from patients with VAP around the world (GarnachoMontero, 2005). This organism has emerged as one of the most problematic pathogens for healthcare institutions worldwide. Carbapenems remain the antibiotics of choice to treat $A$. baumannii due to both a wider spectrum of antibacterial activity and less frequent side effects. The development of resistance did not spare even this group of antimicrobial drugs that is largely due to the selective pressure from antimicrobials especially in ICUs, in addition to its incredible ability to acquire resistance (Fouad et al., 2013).Early detection of such resistance can help the clinician in managing infections, prevent the toxic adverse effect of different antimicrobial agents that may be caused by different trials of empirical treatment and also limit the spread of infections.

In this study, A. baumannii represented the predominant isolated organism from endotracheal aspiration samples of VAP patients (32.6\%), this result was in agreement with many studies as that of Rit et al., (2014) and Chawla (2008)who reported that $A$. baumannii was the most common pathogen in VAP in Pakistan, India, Thailand and Malaysia however, other organisms were often responsible for VAP in Korea and Taiwan Chawla (2008). The difference in incidences of isolated organisms may be due to different communities, different hospital wards and different strategies of infection control applications among countries.

In this study the risk factors that significantly associated with increase infection with carbapenem resistant $A$. baumannii (CRAB) in VAP patients were include; hospital stay > 14 days and prior use of antibiotics. This is similar to results of studies carried out by several investigators as Özgür et al. (2014), Marie et al. (2012), Robertino et al. (2010), they concluded that longer periods of hospitalization, and prior use of antibiotics are the recognized factors increasing the risk of VAP due to multidrug and impenim resistant Acinetobacter infection. On the other hand, there were no statistical significant differences regarding age and sex and presence of CRAB in VAP patients, the same finding concerning age of patients was reported by (Fattouh et al., 2014).

This study revealed that $\mathrm{CRAB}$ rates to impenim, meropenim were relatively high as the resistant rates to impenim was $75 \%$ and to meropenim was $72.7 \%$, these results were in agreement with the results of other studies done in Egypt as that of AlHassan et al. (2013)who reported that A. baumannii isolates resistant rates were $73 \%$ to impenim and / or meropenem, (Al-Agamy et al., 2014) reported that the resistant rates were $70 \%$ to impenem, other authorsalso concluded that High resistance rates to carbapenems have been observed in Egypt, ranging from $75 \%$ to $100 \%$ for imipenem and from $61 \%$ to $77 \%$ for meropenem (Mohamed et al., 2011; Ahmed et al., 2011; Fouad et al., 2013). A. baumannii resistant rate to imipenem was found to be $65 \%$ in 
Saudi Arabia, 95\% in Turkey, 47.9\% in Algeria, $45 \%$ in Tunisia, and $19.14 \%$ in Kuwait (Al agamy et al., 2013; Cicek et al., 2013; Bakour et al., 2013; Ben othman, 2007; Al Sweih et al., 2012). The increased rates of resistant to carbepenems are most probably due uncontrolled extensive use of these drugs.

All A. baumannii isolates were multiple drug resistant (MDR) strains based on resistance to more than two antibiotic groups, these result is consistent with Cherkaoui et al., 2015. Many authors also reported about MDR A. baumannii as Pleg et al., 2008, Cicek et al., 2014. None of the studied isolate was pan drug resistant strain. The same also reported by Cicek et al., 2014.

The present study found $100 \%$ resistant isolates to cefepime, ceftazidime aztreonam, pipracillin and trimethoprim/ sulfemethoxazole, less resistant to pipracillin/ tazobactam, ticarcillin, ticarcillin/clavulanic acid, ciprofloxacin, pefloxacin, gentamycin, tobramycin, minocycline, amikacin, rifampicin and colistin. This results was consistent to some extent with previous studies carried out in Egypt byAl Agamy et al. 2014, Nasr and Attalla, 2012and Mohamed et al., 2011andthey concluded that $A$. baumannii isolates in their studies were $100 \%$ resistant to third and fourth generation cephalosporins and variable results of resistance concerning other antibiotics.

We found that colistin was the most effective antibiotic against $A$. baumannii causing VAP infection as its sensitivity rate was $93.2 \%$ and it had the least resistant rate $(6.8 \%)$ among 18 different antibiotic used for antimicrobial sensitivity test. This result is in agreement with a previous Egyptian study by Al-Agamy et al., 2014who reported that the percentage of colistin susceptibility was $95 \%$. Also our finding is consistent with the finding of other studies that reported $A$. baumannii isolates were $100 \%$ sensitive to colistin such as Fouad et al., (2013), Josheghani et al., (2016), Cherkaoui et al., (2015), Cicek et al., (2013), Abdalhamid et al., (2014). There is tendency to increase using colistin in treatment of VAP caused by A. baumannii as it currently most effective drug (Aydemir et al., 2013; Jean \& Hsueh, 2011). The colistin resistance rate is relatively low may be because its infrequent use (Al-Agamy et al., 2014).

On the other hand some studies reported lower rates of colistin sensitivity as one study in Egypt by Mohamed et al., (2011)) as they reported it was $82.2 \%$ and while in Saudia Arabia it was $70.9 \%$ (Al-Agamy et al., 2013).

The most prevalent resistant mechanism in CRAB isolates is carbapemem hydrolyzing class D $\beta$-lactamases (CHDLs) that can be divided into four main subgroups, and encoded by intrinsic bla $a_{\text {OXA-51-like gene and }}$ the acquired carbapenemase genes including bla $a_{\text {OXA-23-like, }}$ bla $a_{\text {OXA-24-like, }}$ bla $a_{\text {OXA-58- like }}$ genes (Adams-Haduch et al., 2006).

In this studybla $a_{\text {OXA-23gene was most }}$ common virulent oxacillinase gene detected among carbepenem resistant A. baumannii, this in agreement with many studies reported that $b l a_{\text {OXA-23 }}$ was the most frequent type of carbapenamase identified (Al agamy et al., 2013; Cicek et al., 2013; Abbot et al., 2013; Al Hassan et al., 2013; Fouad et al., 2013). The percentage of bla $a_{\text {OXA-23-like gene }}$ detected in impenem resistant isolates were $69.7 \%(23 / 33)$, this result is in agreement with Zowawi et al., 2015; Luo et al., 2015, different percentages of presence of bla $a_{\text {OXA- }}$ 23-like gene were reported in Egypt as 50\% (Al Agamy et al., 2014), 52.9\% (Al Hassan 
et al., 2013), 100\% by Fouad et al. 2013, and others also reported all over the world as those reported by Cherkaoue et al., 2015 (51.8\%), Val et al., 2015 (85\%), 85.7\% ElAbd et al., 2014and 100\% Rolain et al., 2016.

None of the impenem resistant isolates were positive for $b l a_{\text {OXA-24-like or }}$ bla $a_{\text {OXA-58 }}$ like genes this result was in agreement with Rolain et al., (2016). However bla OXA-58like, and bla $a_{\text {OXA-24/40-like genes were }}$ detected in lower rate than of bla $a_{\mathrm{OXA}-23}$-like genes in many studies in Egypt as that by $\mathrm{Al}$ Agamy et al., (2014)who reported that $A$. baumannii carrying $b a_{\text {OXA-58-like gene were }}$ $5 \%$ and that carrying bla $a_{\mathrm{OXA}-24 / 40}$-like gene is
$7.5 \%$, and another study by AlHassan et al.(2013) reported that the percentage of $b l a_{\text {OXA-40, }}$, and $b l a_{\text {OXA-58 }}$ were $2.9 \%$, and $14.7 \%$, respectively.

However carbapenem resistance of $A$. baumanniihas mostly related to the production of bla $a_{\text {OXA-58 }}$ in other countries as Italy and Turkey (Metan et al., 2013, Migliavacca et al., 2013).

Moreoverbla $a_{\text {OXA-24-like gene was detected }}$ with variable rates inmany countries as Saudi Arabia from 4-45\% (Al agamy, 2014, Al Arfaj, 2011), Poland (Nowak et al., 2012), Spain (Villalon, 3013) and in United states (Qi et al., 2007).

Table.1 Primer used for detection of genes encoding oxacillinases in A. baumannii isolates

\begin{tabular}{|c|c|c|}
\hline Primer & Nucleotide Sequence $\left(5^{\prime}-3^{\prime}\right)$ & $\begin{array}{c}\text { Amplicon } \\
\text { size }\end{array}$ \\
\hline OXA-23F & GATCGGATTGGAGAACCAGA & \multirow{2}{*}{501} \\
\hline OXA-23R & ATTTCTGACCGCATTTCCAT & \\
\hline OXA-51F & TAATGCTTTGATCGGCCTTG & \multirow{2}{*}{353} \\
\hline OXA-51R & TGGATTGCACTTCATCTTGG & \\
\hline OXA24 F & GGTTAGTTGGCCCCCTTAAA & \multirow{2}{*}{246} \\
\hline OXA24 R & AGTTGAGCGAAAAGGGGATT & \\
\hline OXA58F & AAGTATTGGGGCTTGTGCTG & \multirow{2}{*}{599} \\
\hline OXA58R & CCCCTCTGCGCTCTACATAC & \\
\hline
\end{tabular}

Table.2 Risk factors associated with isolation of imipenem sensitive and resistant A. baumannii among VAP patients

\begin{tabular}{|c|c|c|c|c|c|c|c|}
\hline \multirow{2}{*}{\multicolumn{2}{|c|}{ Risk factors }} & \multicolumn{2}{|c|}{$\begin{array}{c}\text { Imipenem resistant } \\
\text { A. baumannii(33) }\end{array}$} & \multicolumn{2}{|c|}{$\begin{array}{c}\text { Imipenem sensitive } \\
\text { A. baumannii(11) }\end{array}$} & \multirow[t]{2}{*}{$\mathrm{X}^{2}$} & \multirow[t]{2}{*}{$P$ value } \\
\hline & & No. & $\%$ & No. & $\%$ & & \\
\hline \multirow[t]{2}{*}{ Age } & $\leq 40$ & 14 & $42.4 \%$ & 5 & $45.5 \%$ & \multirow[t]{2}{*}{0.32} & \multirow[t]{2}{*}{0.86} \\
\hline & $>40$ & 19 & $57.6 \%$ & 6 & $54.5 \%$ & & \\
\hline \multirow{2}{*}{$\begin{array}{l}\text { Length of } \\
\text { hospital stay: }\end{array}$} & <14days & 1 & $3 \%$ & 3 & $27.3 .1 \%$ & \multirow[t]{2}{*}{5.73} & \multirow[t]{2}{*}{$0.016^{*}$} \\
\hline & $>$ 14days & 32 & $97 \%$ & 8 & $72.7 \%$ & & \\
\hline \multirow{2}{*}{$\begin{array}{l}\text { Prior use of } \\
\text { antibiotics } \\
\end{array}$} & Yes & 29 & $87.9 \%$ & 5 & $45.5 \%$ & \multirow[t]{2}{*}{6.21} & \multirow[t]{2}{*}{$0.012 *$} \\
\hline & No & 4 & $12.1 \%$ & 6 & $54.5 \%$ & & \\
\hline \multirow[t]{2}{*}{ Sex } & Male & 16 & $48.5 \%$ & 5 & $45.5 \%$ & \multirow[t]{2}{*}{0.03} & \multirow[t]{2}{*}{0.86} \\
\hline & Female & 17 & $51.5 \%$ & 6 & $54.5 \%$ & & \\
\hline
\end{tabular}

* Significant 
Fig.1 Percentages of antimicrobial resistance among A. baumanni isolates

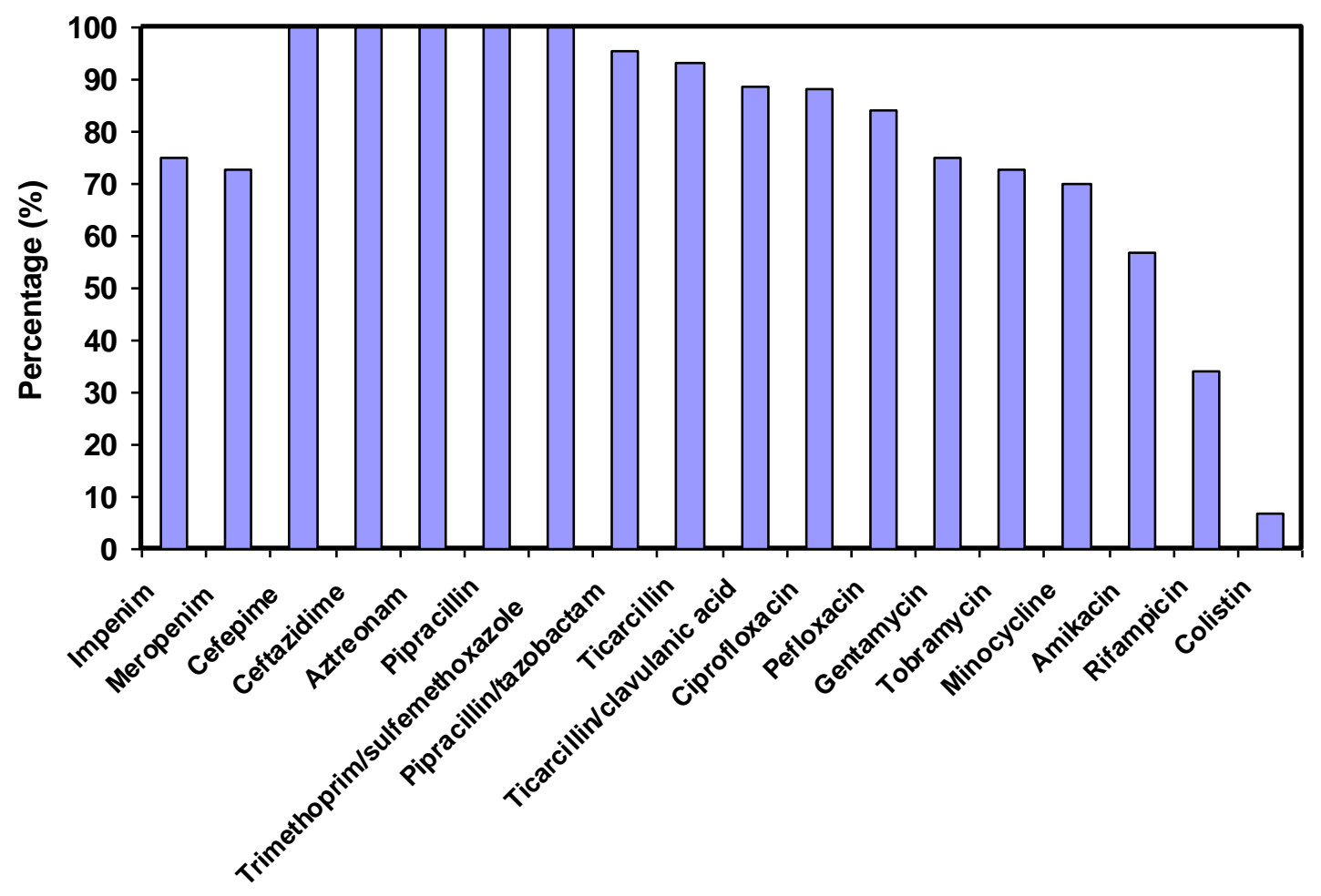

Fig.2 Multiplex PCR results of some A. baumannii isolates show intrinsic blaOXA-51-like gene at353 (lanes 1 to 4) and the acquired blaOXA-23-like gene at501 bp (lanes2 to 4).

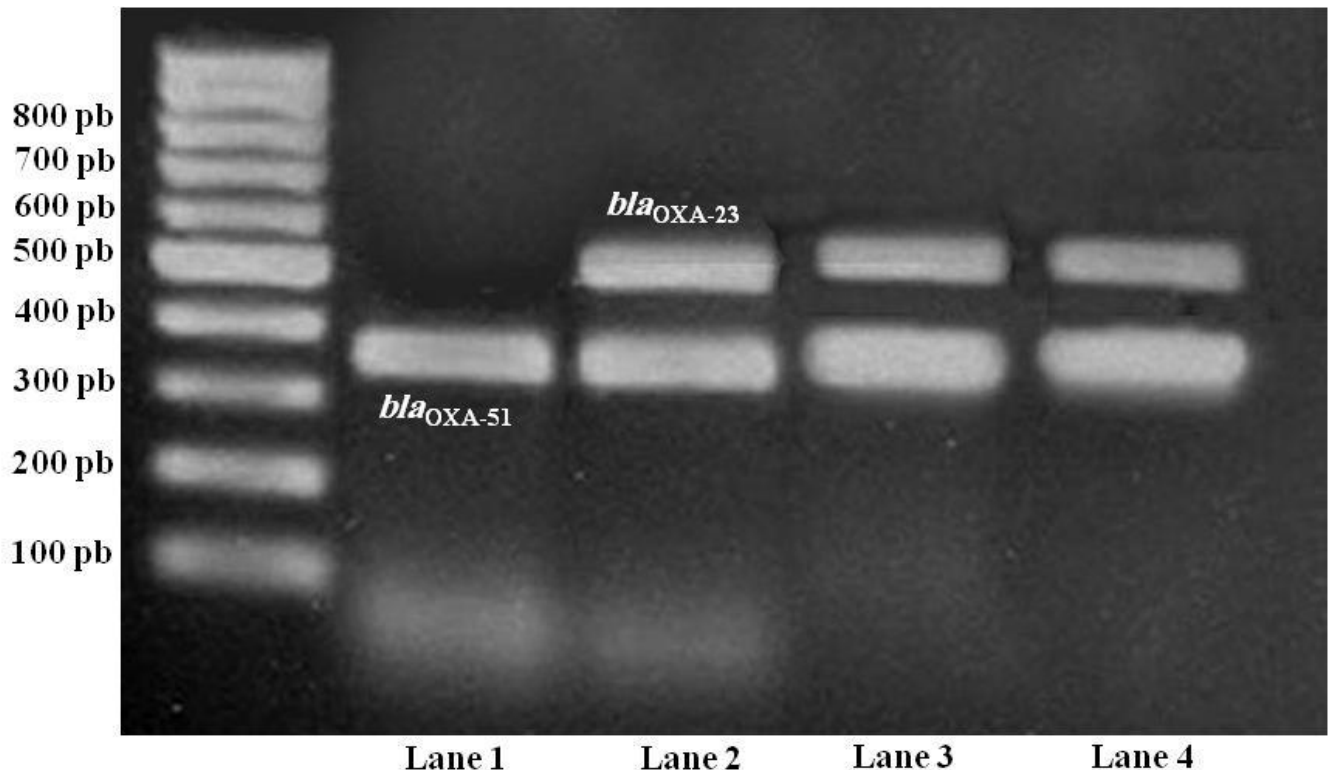


These variable rates of detecting different types of oxacillinases are mostly due to different antibiotic treatment strategy that may affect the evolutionary direction of $A$. baumannii.

All of the studied isolates including carbepenem sensitive and resistant strains were carrying $b l a_{\text {OXA-51 }}$-like gene $(100 \%)$, this in agreement with El Abd et al., 2014 and many other author as Howard et al., 2012; Lee et al., 2012who concluded that this gene occur naturally in $A$. baumannii and it is chromosomally located and widely prevalent and it can be used as a supplementary tool to identify A. baumannii at species level.

In this study there were 33 carbapenem resistant strains 23 of them were carrying both bla $_{\text {OXA-51-like gene and }}$ laXA-23-like $_{\text {OX }}$ gene. There were 11 resistant strains carrying only $b l a_{\text {OXA-51 }}$-like gene and no other CHDLs genes detected, this may be due to presence of other resistance mechanisms as acquisition of met allo $\beta$-lactamases.

This study had some limitation as a relatively small number of $A$. baumannii that was due to low numbers of VAP cases in comparison to other types of pneumonia admitted in our hospitals during the period of study. Other limitation of this study is being it is a single center study and our finding may not be applied to other hospitals in Egypt.

Multicenter molecular based epidemiological studies of A. baumannii with longer surveillance duration are recommended for better understanding of the prevalence and distribution of the carbapemase genes, that can help in prevention of the spread of carbapenem resistant A. baumannii in Egyptian hospitals and support the determination of priorities for local intervention actions. Also careful choose of empirical antimicrobial agent in VAP patients should be of great concern.

In conclusion, this study highlights multidrug resistant $A$. baumannii as the main cause VAP in our ICUs. Carbapenem resistance was significant in the studied isolates; the most common gene responsible for this resistance was bla $a_{\mathrm{OXA}-23}$-like gene. Colistin is the most effective antimicrobial agent against the studied isolates. The recovery of these resistant strains for the first time is emerging threat in our hospitals, as it will contribute in increasing patient hospital stay and associated costs; also it will lead to some difficulties in choice of empirical treatment in VAP patients. Monitoring the use of carbapenems and strict infection control measures are required for controlling the spread of the resistance and for optimizing the treatment of patients with $A$. baumannii.

\section{Conflict of interest}

The authors declare no conflict of interest This research did not receive any specific grant from funding agencies in the public, commercial or not-for- profit sector.

\section{Abbreviations}

VAP:Ventilator-associated pneumonia, MALDI-TOF MS: Matrix-assisted laser desorption ionization-time of flight mass spectrometry,MDR: multidrug-resistant, CRAB: carbapenem resistant $A$. baumannii, CHDLs:hydrolyzing class D $\beta$-lactamases

\section{References}

Abbott, I., Cerqueira, G.M., Bhuiyan, S., Peleg, A.Y. 2013. Carbapenem resistance in Acinetobacter baumannii: laboratory challenges, mechanistic 
insights and therapeutic strategies. Expert. Rev. Anti. Infect. Ther., 1, 395-409.

Abdalhamid, B., Hassan, H., Itbaileh, A., Shorman, M., 2014. Characterization of carbapenem-resistant Acinetobacter baumannii clinical isolates in a tertiary care hospital in Saudi Arabia. New Microbiologica, 37, 65-73.

Adams-Haduch, J.M., Paterson, D.L., Sidjabat, H.E., et al. 2008. Genetic basis of multidrug resistance in Acinetobacter baumannii clinical strains at a tertiary medical center in Pennsylvania. Antimicrob. Agents Chemother., 52, 3837-3843.

Ahmed, S.H., Abdelwahab, S.F., Hasanen, A.M., Mohammed, D.S., 2011. Multidrug resistant Egyptian isolates of Acinetobacter baumannii. J. Am. Sci. 7, 1013-9.

Al-Agamy, M.H., Khalaf, N.G., Tawfick, M.M., Shibl, A.M., El Kholy, A., 2014. Molecular characterization of carbapenem-insensitive Acinetobacter baumannii in Egypt. Int. J. Infect. Dis., 14, 22:49-54.

Al-Agamy, M.H., Shibl, A.M., Ali, M.S., Khubnani, H., Radwan, H.H., Livermore, D.M., 2013. Distribution of $\beta$-lactamases in carbapenem-nonsusceptible Acinetobacter baumannii in Riyadh, Saudi Arabia. J. Glob. Antimicrob. Res., 2(1), 17-21

Al-Arfaj, A.A., Ibrahim, A.S., Somily, A.M., Al-Salamah, A.A., 2011. Geneticbasis of carba-penem resistance in Acinetobacter clinicalisolates in Saudi Arabia. Afr. J. Biotech., 10, 14186-96.

Al-Hassan, L., El Mehallawy, H., Amyes, S.G., 2013. Diversity in Acinetobacter baumannii isolates from pediatric cancer patients in Egypt. Clin. Microbiol. Infect. 19(11), 1082-8.

Al-Sweih, N.A., Al-Hubail, M., Rotimi,
V.O., 2012. Three distinct clones of carbapenem-resistant Acinetobacter baumannii with high diversity of carbapenemases isolated from patients in two hospitals in Kuwait. J. Infect. Public. Health, 5, 102-8.

Antunes, L., Visca, P., Towner, K.J., 2014.Acinetobacter baumannii: evolution of a global pathogen. Pathog. Dis., 71, 292-301.

Aydemir, H., Akduman, D., Piskin, N., Comert, F., Horuz, E., Terzi, A., Kokturk, F., Ornek, T., Celebi, G., 2013. Colistin vs. the combinationof colistin and rifampicin for the treatment of carbapenem-resistant Acinetobacter baumannii ventilatorassociated pneumonia. Epidemiol. Infect., 141, 1214-1222.

Bakour, S., Touati, A., Sahli, F., Ameur, A.A., Haouchine, D., Rolain, J.M., 2013. Antibiotic resistance determinants of multidrug-resistant Acinetobacter baumannii clinical isolates in Algeria. Diagn. Microbiol. Infect. Dis., 76: 529-31.

Bantar, C., Famiglietti, A., Radice, M., Quinteros, M. Antimicrobial Committee \& SIR Participants Group, 2008. A 7-year national survey on bacterial resistance in bronchoalveolar lavage from patients hospitalized in Argentina. Diagn. Microbiol. Infect. Dis. 60, 65-69.

Baxter, A.D., Allan, J., Bedard, J., et al., 2005. Adherence to simple and effective measures reduces the incidence of ventilator-associated pneumonia. Can. J. Anesth., 5, 53541.

Ben Othman, A., Zribi, M., Masmoudi, A., Abdellatif, S., Ben Lakhal, S., Fendri, C., 2007. Phenotypic and molecular epidemiology of Acinetobacter baumannii strains isolated in Rabta Hospital, Tunisia. Arch. Inst. Pasteur. 
Tunis, 84, 11-9.

Bush, K., Jacoby, G.A., 2010. Updated functional classification of lactamases. Antimicrob. Agent Chemother., 54, 969-976.

Chawla, R., 2008. Epidemiology, etiology, and diagnosis of hospital-acquired pneumonia and ventilator-associated pneumonia in Asian countries. Am. J. Infect. Control, 36(4 Suppl), S93-100.

Cherkaoui, A., Emonet, S., Renzi, G., Schrenzel, J., 2015. Characteristics of multidrug-resistant Acinetobacter baumannii strains isolated in Geneva during colonization or infection. Ann. Clin. Microbiol. Antimicrob. 11, $14: 42$.

Cicek, A.C., Saral, A., Iraz, M., Ceylan, A., Duzgun, A.O., Peleg, A.Y., Sandalli, C., 2014. OXA- and GES-type $\beta$ lactamases predominate in extensively drug-resistant Acinetobacter baumannii isolates from a Turkish University Hospital, Clin. Microbiol. Infect., 20(5), 410-5

Dai, W., Huang, S., Sun, S., Cao, J., Zhang, L., 2013. Nosocomial spread of carbapenem-resistant Acinetobacter baumannii (types ST75 and ST137) carrying bla $a_{\text {OXA-23-like gene with an }}$ upstream ISAba1 in a Chinese hospital. Infection Genetics and Evol., 14, 98-10.

Elabd, F.M., Al-Ayed, M.S., Asaad, A.M., Alsareii, S.A., Qureshi, M.A., Musa, H.A., $2015 . \quad$ Molecular characterization of oxacillinases among carbapenem-resistant Acinetobacter baumannii nosocomial isolates in a Saudi hospital. J. Infect. Public Health, 8(3), 242-7.

Fattouh,M. and Nasr El Din, 2014. Emergence of Carbapenem-Resistant Acinetobacter baumannii in the Intensive Care Unit in Sohag University Hospital, Egypt. Int. J.
Curr. Microbiol. App. Sci., 3(4), 732744.

Fouad, M., Attia, A.S., Tawakkol, W.M.,Hashem, A.M., 2013. Emergence of carbapenem-resistant Acinetobacter baumannii harboring the OXA-23 carbapenemase in intensive care units of Egyptian hospitals. Int. J. Infect. Dis., 17(12): e1252-4

Garnacho-Montero, J., Ortiz-Leyba, C., Fernandez-Hinojosa, E., et al., 2005.Acinetobacter baumannii ventilator-associated pneumonia: epidemiological and clinical findings. Intensive Care Med., 31, 649-5.

Howard, A., O’Donoghue, M., Feeney, A., Sleator. R.D., 2012.Acinetobacter baumannii: an emerging opportunistic pathogen. Virulence, 3, 243-50.

Jean, S.S., Hsueh, P.R., 2011. Current review of antimicrobial treatment of nosocomial pneumonia caused by multidrug-resistant pathogens. Expert Opin. Pharmacother. 12, 2145-2148.

Josheghani, S.B., Moniri, R., Firoozeh, F., Sehat, M., Dastehgoli, K., Koosha, H., Farahani, R.K., 2016 Emergence of bla OXA-Carrying Carbapenem Resistance in Multidrug-Resistant Acinetobacter baumannii in the Intensive Care Unit. Iran Red Crescent Med. J., doi:10.5812/ircmj.27327

Lee, Y.T., Kuo, S.C., Chiang, M.C., et al., 2011. Emergence of carbapenemresistant non-baumannii species of Acinetobacter harboring a bla OXA-51- $^{-}$ like gene that is intrinsic to $A$. baumannii. Antimicrob. Agents Chemother., 56, 1124-1127.

Lemos, E., de la Hoz, F., Einarson, T., McGhan, W., Quevedo, E., Castañeda, C., et al., 2014. Carbapenem resistance and mortality in patients with Acinetobacter baumannii 
infection: systematic review and metaanalysis. Clin. Microbiol. Infect., 20, 416-423.

Luo, T.L., Rickard, A.H., Srinivasan, U., Kaye, K.S., Foxman, B., 2015. Association of bla $a_{\mathrm{OXA}-23}$ and bap with the persistence of Acinetobacter baumannii within a major healthcare system. Front. Microbiol., 6, 182.

Marie, K., Rolain, J.M., 2012. Emergence of resistance to carbapenems in Acinetobacter baumannii in Europe: clinical impact and therapeutic options. Int. J. Antimicrob. Agents, 39, 105-14.

Merkier, A.K., Centron, D., 2006. Bla (OXA-51)-type beta-lactamase genes are ubiquitous and vary within a strain in Acinetobacter baumannii. Int. J. Antimicrob. Agents, 28, 110-113.

Metan, G., Sariguzel, F., Sumerkan, B., Reijden, T.V., Dijkshoorn, L., 2013. Clonal diversity and high prevalence of OXA-58 among Acinetobacter baumannii isolates from blood cultures in a tertiary care centre in Turkey. Infect. Genet. Evol., 14, 92-7.

Migliavacca, R., Espinal, P., Principe, L., Drago, M., Fugazza, G., Roca, I., et al., 2013. Characterization of resistance mechanisms and genetic relatedness of carbapenem-resistant Acinetobacter baumannii isolated from blood, Italy. Diagn. Microbiol. Infect. Dis., 75, 180-6.

Mohamed, N.M., Raafat, D., 2011. Phenotypic and genotypic detection of met allo-beta-lactamases in imipenemresistant Acinetobacter baumannii isolated from a tertiary hospital in Alexandria, Egypt. Res. J. Microbiol., 6, 750-60.

Nasr, R.A., Attalah, M.F., 2012. Molecular epidemiology of nosocomial Acinetobacter baumannii isolates. Nature and Sci., 10, 76-82.
Nowak, P., Paluchowska, P., Budak, A., 2012. Distribution of bla $a_{\text {OXA }}$ genes among carbapenem-resistant Acinetobacter bau-mannii nosocomial strains in Poland. New Microbiol., 35, 317-25.

Özgür, E.S., Horasan, E.S., Karaca, K., Ersöz, G., Naycı Atıs, S. 2014. Ventilator-associated pneumonia due to extensive drug-resistant Acinetobacter baumannii: Risk factors, clinical features, and outcomes. American J. Infection Control, 42, 206-8.

Peleg, A.Y., Seifert, H., Paterson, D.L., 2008.Acinetobacter baumannii: emergence of a successful pathogen. Clin. Microbiol. Rev., 21, 538-582.

Poirel, L., Nordmann, P., 2006. Carbapenem resistance in Acinetobacter baumannii: mechanisms and epidemiology. Clin. Microbiol. Infect., 12, 826-836.

Qi, C., Malczynskim, M., Parker, M., Scheetz, M.H., 2008. Characterization of genetic diversity of carbapenemresistant Acinetobacter baumannii clinical strains collected from2004 to 2007. J. Clin. Microbiol., 46, 1106-9.

Rit, K., Chakraborty, B., Saha, R., Majumder, U., 2014. Ventilator associated pneumonia in a tertiary care hospital in India: Incidence, etiology, risk factors, role of multidrug resistant pathogens. Int. J. Med. Public Health, 4, 51-6.

Robertino, M., Mera, L., Miller, A., AmrineMadsen, H., Sahm, D.F., 2010.Acinetobacter baumannii 20022008: increase of carbapenemassociated multiclass resistance in the United States. Microb. Drug Resist, 16, 209-15.

Rolain, J.M., Loucif, L., Al-Maslamani, M., Elmagboul, E., Al-Ansari, N., TajAldeen, S., Shaukat, A., Ahmedullah, H., Hamed, M., 2016. Emergence of 
multidrug-resistant Acinetobacter baumannii producing OXA-23 Carbapenemase in Qatar. New Microbes New Infect, 23, 11:47-51.

Vali, L., Dashti, K., Opazo-Capurro, A.F., Dashti, A.A., Al Obaid, K., Evans, B.A., 2015. Diversity of multi-drug resistant Acinetobacter baumannii population in a major hospital in Kuwait. Front Microbiol., 23, 6:743.

Villalon, P., Valdezate, S., Medina-Pascual, M.J., Carrasco, G., Vin-del, A., SaezNieto, J.A., 2013. Epidemiology of the Acinetobacter-derived cephalosporinase, carbapenemhydrolysing oxacil-linase and met allo- -lactamase genes, and of commoninsertion sequences, in epidemic clones of Acinetobacter baumannii from Spain. J. Antimicrob. Chemother., 68, 550-3.

Woodford, N., Ellington, M.J., Coelho, J.M., Turton, J.F., Ward, M.E., Brown, S., Amyes, S.G., Livermore, D.M., 2006. Multiplex PCR for genes encoding prevalent OXA carbapenemases in Acinetobacter spp. Int. J. Antimicrob. Agents, 27(4), 351-3

Zowawi, H.M., Sartor, A.L., Sidjabat, H.E., Balkhy, H.H., Walsh, T.R., Al Johani, S.M., et al., 2015. Molecular epidemiology of carbapenem-resistant Acinetobacter baumannii isolates in the Gulf Cooperation Council States: dominance of OXA-23-type producers. J. Clin. Microbiol., 53, 896-903.

\section{How to cite this article:}

Ghada E. Amr and Ghada M. Abdel Razek. 2016. Characterization of Carbapenem Resistant Acinetobacter baumannii causing Ventilator associated Pneumonia in ICUs of Zagazig University Hospitals, Egypt. Int.J.Curr.Microbiol.App.Sci. 5(12): 660-671. doi: http://dx.doi.org/10.20546/ijcmas.2016.512.074 